\title{
Quorum sensing control of phosphorus acquisition in Trichodesmium consortia
}

\author{
Benjamin AS Van Mooy ${ }^{1}$, Laura R Hmelo ${ }^{1,5}$, Laura E Sofen ${ }^{1}$, Shawn R Campagna ${ }^{2}$, \\ Amanda L May², Sonya T Dyhrman ${ }^{3}$, Abigail Heithoff ${ }^{3}$, Eric A Webb ${ }^{4}$, Lily Momper ${ }^{4}$ \\ and Tracy J Mincer ${ }^{1}$ \\ ${ }^{1}$ Department of Marine Chemistry and Geochemistry, Woods Hole Oceanographic Institution, Woods Hole, \\ MA, USA; ${ }^{2}$ Department of Chemistry, University of Tennessee, Knoxville, TN, USA; ${ }^{3}$ Department of Biology, \\ Woods Hole Oceanographic Institution, Woods Hole, MA, USA and ${ }^{4}$ Department of Biological Sciences, \\ University of Southern California, Los Angeles, CA, USA
}

\begin{abstract}
Colonies of the cyanobacterium Trichodesmium are abundant in the oligotrophic ocean, and through their ability to fix both $\mathrm{CO}_{2}$ and $\mathrm{N}_{2}$, have pivotal roles in the cycling of carbon and nitrogen in these highly nutrient-depleted environments. Trichodesmium colonies host complex consortia of epibiotic heterotrophic bacteria, and yet, the regulation of nutrient acquisition by these epibionts is poorly understood. We present evidence that epibiotic bacteria in Trichodesmium consortia use quorum sensing (QS) to regulate the activity of alkaline phosphatases (APases), enzymes used by epibionts in the acquisition of phosphate from dissolved-organic phosphorus molecules. A class of QS molecules, acylated homoserine lactones (AHLs), were produced by cultivated epibionts, and adding these AHLs to wild Trichodesmium colonies collected at sea led to a consistent doubling of APase activity. By contrast, amendments of (S)-4,5-dihydroxy-2,3-pentanedione (DPD)-the precursor to the autoinducer-2 (Al-2) family of universal interspecies signaling molecules-led to the attenuation of APase activity. In addition, colonies collected at sea were found by high performance liquid chromatography/mass spectrometry to contain both AHLs and Al-2. Both types of molecules turned over rapidly, an observation we ascribe to quorum quenching. Our results reveal a complex chemical interplay among epibionts using AHLs and Al-2 to control access to phosphate in dissolved-organic phosphorus.

The ISME Journal (2012) 6, 422-429; doi:10.1038/ismej.2011.115; published online 8 September 2011

Subject Category: microbe-microbe and microbe-host interactions

Keywords: quorum sensing; Trichodesmium; cyanobacteria; acylated homoserine lactone; autoinducer-2
\end{abstract}

\section{Introduction}

Cyanobacteria of the genus Trichodesmium are key members of the phytoplankton community in the oligotrophic regions of the ocean. Nutrients are very scarce in these environments, yet Trichodesmium are highly successful, contributing a significant fraction of $\mathrm{CO}_{2}$ fixation in their environment (Capone et al., 1997). One of the key adaptations of Trichodesmium to its environment is the ability to fix $\mathrm{N}_{2}$ (Capone et al., 2005), which is highly abundant. However, the scarcity of other nutrients can limit the rates at which these organisms fix both $\mathrm{N}_{2}$ and $\mathrm{CO}_{2}$ (Sañudo-Wilhelmy et al., 2001; Mills

Correspondence: BAS Van Mooy, Department of Marine Chemistry and Geochemistry, Woods Hole Oceanographic Institution, WHOI, MS\#4, Woods Hole, MA 02543, USA.

E-mail: bvanmooy@whoi.edu

${ }^{5}$ Current address: Department of Microbiology, University of Washington, Seattle, WA, USA.

Received 13 May 2011; revised 15 July 2011; accepted 15 July 2011; published online 8 September 2011 et al., 2004). Phosphorus limitation of Trichodesmium has been predicted by models of ocean biogeochemistry (Krishnamurthy et al., 2007), and demonstrated in field studies employing a variety of incubation-based approaches (Sañudo-Wilhelmy et al., 2001; Mills et al., 2004; Moutin et al., 2005; Krauk et al., 2006; White et al., 2006; Webb et al., 2007). Phosphate concentrations can be very low in the tropical and subtropical oceans, particularly the western North Atlantic (Wu et al., 2000; CavenderBares et al., 2001; Lomas et al., 2010). It is clear that Trichodesmium meet their phosphorus demand through expression of alkaline phosphatases (APases) (Sohm and Capone, 2006; Hynes et al., 2009; Orchard et al., 2009; Orchard et al., 2010), enzymes used to hydrolyze bioavailable phosphate from comparatively abundant dissolved-organic phosphorus molecules (Karl et al., 2001; Lomas et al., 2010).

In the open ocean, Trichodesmium colonies contain a diversity of other types of cells (Paerl et al., 1989; Nausch, 1996; Sheridan et al., 2002; Hewson et al., 2009; Hmelo, 2010), including heterotrophic 
bacterial epibionts that, together with Trichodesmium, form a consortium that is highly adapted to the phosphorus-depleted conditions of the open ocean. Cell densities of epibionts in Trichodesmium colonies can be three orders of magnitude greater than cell densities in surrounding waters (Sheridan et al., 2002), and APase expression by these epibionts is frequently observed (Dyhrman et al., 2002; Hynes et al., 2009). However, the distribution of APase activity among epibionts and Trichodesmium within colonies is highly variable even within the same environment (Dyhrman et al., 2002; Hynes et al., 2009), and the mechanisms driving the variability in this behavior are unknown. Proteobacteria related to those within Trichodesmium consortia (Hewson et al., 2009; Hmelo, 2010) are known to employ quorum sensing (QS; a cell-density dependent signaling system), based on acylated homoserine lactones (AHLs; Supplementary Figure 1) to coordinate their behavior (Wagner-Döbler et al., 2005; Case et al., 2008). Furthermore, it was recently shown that AHL-based QS is sustainable at the cell densities typical of Trichodesmium colonies (Hmelo and Van Mooy, 2009; Hmelo et al., in press). Given the importance of APases to phytoplankton in the subtropical oceans where phosphate is scarce (Perry, 1972; Sañudo-Wilhelmy et al., 2001; Dyhrman et al., 2002; Hynes et al., 2009; Orchard et al., 2009), and our limited understanding of QS in these same environments, we sought to explore the relationship between APase activity and AHL-based QS within Trichodesmium consortia.

\section{Methods}

Sampling was conducted in the subtropical North Atlantic Ocean during two cruises. The first cruise was to the Bermuda Atlantic Time-Series station $\left(31.8^{\circ} \mathrm{N} 64.1^{\circ} \mathrm{W}\right)$, aboard the R/V Atlantic Explorer in September 2008. The second cruise was a transect from Woods Hole, MA, USA, to Barbados aboard the $\mathrm{R} / \mathrm{V}$ Oceanus in November 2010. Sampling in the subtropical North Pacific Ocean was conducted aboard the R/V Kilo Moana in July 2010 at the approximate location of the Hawaiian Ocean Time-series station $\left(22.7^{\circ} \mathrm{N} 158^{\circ} \mathrm{W}\right)$. Colonies of Trichodesmium were collected at sea (roughly from the top $25 \mathrm{~m}$ ), with a $130-\mu \mathrm{m}$ mesh plankton net. Before being processed as described below, individual colonies were carefully picked and then gently rinsed twice with $0.2-\mu \mathrm{m}$-filtered local seawater, to remove organisms not closely associated with the colonies.

During the first cruise to the North Atlantic, epibionts were isolated by streaking Trichodesmium colonies on seawater-based agar plates with tryptone $\left(1 \mathrm{gl}^{-1}\right)$, and without tryptone. Epibiont colonies that grew on the plates were restreaked for purity, and shipped back to the laboratory in Woods Hole. Phylogeny of the epibionts was assessed using $16 \mathrm{~S}$
rRNA gene sequences. Epibionts were grown overnight in seawater containing tryptone $\left(\mathrm{gl}^{-1}\right)$, their DNA was extracted using standard methods, and 16S rRNA genes were amplified using the forward primer $27 \mathrm{~F}$ (5'-AGAGTTTGATCMTGGCTCAG-3') and reverse primer 1492R (5'-TACGGYTACCTTGTTA CGACTT-3') as described (Hmelo, 2010). End sequencing was performed offsite either by MWG-Operon (Huntsville, AL, USA) or Agencourt Biosciences (Beverly, MA, USA). Sequences were analyzed and phylogenetic trees constructed as described (Hmelo, 2010).

Cultured epibionts were subsequently screened for AHL production. Cultures were grown overnight at room temperature in seawater containing tryptone $\left(1 \mathrm{gl}^{-1}\right)$. These seawater cultures were then spotted onto soft agar plates seeded with the AHL biosensor Agrobacterium tumefaciens NTL4(pZLR4) as described (Farrand et al., 2002; Hmelo et al., in press). Epibiont cultures yielding a positive response to the biosensor were further screened for the presence of AHLs by high performance liquid chromatography/tandem mass spectrometry (HPLC/ MS/MS) as described (Hmelo et al., in press).

Incubations were conducted with Trichodesmium colonies during the second cruise in the North Atlantic and during the cruise in the North Pacific. Incubations were initiated by placing Trichodesmium colonies in $0.2-\mu \mathrm{m}$-filtered local seawater, and then amending these incubations with AHLs or autoinducer-2 (AI-2) to a total initial concentration of $\sim 500 \mathrm{nmol} \mathrm{l}^{-1}$. The incubations were maintained under approximately $10 \%$ surface photosynthetically active radiation at in situ temperatures. All incubations were conducted in triplicate. After $24 \mathrm{~h}$, APase activities of Trichodesmium colonies were determined; in the North Atlantic, APase assays were conducted with 6,8-difluoro-4-methylumbelliferyl phosphate as described by Orchard et al. (2009), whereas in the North Pacific, the assays were conducted with 4-methylumbelliferyl phosphate as described by Hoppe (1993) and adapted by Hmelo et al. (in press). Cell-specific APase activities were assessed by microscopy as described (Dyhrman et al., 2002).

In the North Pacific, samples were taken for AHL and AI-2 analysis from both fresh Trichodesmium colonies and the aforementioned 24-h incubations. For AHL analysis, samples were spiked with a ${ }^{13}$ C-labeled C8-HSL (Supplementary Figure 1) as a recovery standard, and immediately extracted three times with ethyl acetate $(0.1 \%$ formic acid). The extracts were dried under nitrogen, shipped in liquid nitrogen to the laboratory in Woods Hole, and analyzed by HPLC/MS/MS as described (Hmelo et al., in press). As described by Campagna et al. (2009), samples for AI-2 analysis were first spiked with ${ }^{13} \mathrm{C}$-labeled AI-2 as a recovery standard. After this, tagging agent was added to derivatize and stabilize AI-2 (Campagna et al., 2009). Finally, the samples were frozen at $-80^{\circ} \mathrm{C}$, shipped on dry ice to 
the laboratory at the University of Tennessee, and analyzed by HPLC/MS/MS as described (Campagna et al., 2009). Process blanks were collected regularly (approximately every 15th extraction) using the same $0.2-\mu \mathrm{m}$-filtered seawater used to set up the aforementioned incubations. The concentrations of AHLs and AI-2 through time in the incubations were fit with a first-order exponential curve to determine their degradation rate (Hmelo and Van Mooy, 2009), which was then used to calculate the half-life of the molecules.

\section{Results and discussion}

Stimulation of APase activity by saturated AHLs During our first cruise to the oligotrophic western North Atlantic Ocean, we collected Trichodesmium colonies and isolated bacterial epibionts from these colonies. Of the 141 isolates we obtained, genera from Gammaproteobacteria (24\%) and Alphaproteobacteria (27\%) were prevalent (Supplementary Figure 2). In Vibrio isolates, we observed the production of 3-oxo functionalized, medium chainlength AHLs (e.g. 3-oxo-octanoyl homoserine lactone (3-oxo-C8-HSL); Supplementary Table 1 and Supplementary Figure 1), similar to what has been observed in Vibrio isolated from corals (Tait et al., 2009a). By contrast, the Erythrobacter isolates produced saturated (i.e., no 3-oxo group), long chain-length AHLs (e.g., tetradecane homoserine lactone (C14-HSL); Supplementary Table 1 and Supplementary Figure 1). The distribution of AHLs produced by the Erythrobacter isolates is similar to AHL distributions reported in other Alphaproteobacteria (Wagner-Döbler et al., 2005), and Alphaproteobacteria were recently found to be prevalent within Trichodesmium consortia by using cultivation-independent methods (Hmelo, 2010). Although the few AHL-producing Erythrobacter we isolated probably represented only a fraction of the AHLproducing epibionts within Trichodesmium colonies, Decho et al. (2009) reported that the same saturated, long-chain AHLs were also prevalent in natural cyanobacterial mat communities. These observations led us to surmise that if AHL-based QS was occurring between Trichodesmium epibionts, then saturated, long chain-length AHLs would likely be involved.

On the subsequent cruise to the oligotrophic, western North Atlantic Ocean, we conducted incubation experiments designed to test whether AHLs affected rates of APase activity in Trichodesmium colonies. We constructed a cocktail of saturated long chain-length AHLs (C10-, C12- and C14-HSL), which was added to incubations containing Trichodesmium colonies. At three stations across the western North Atlantic, we consistently found that AHLs elicited a roughly two-fold increase in APase activities (Kruskal-Wallis, $P=0.0064$; Figure 1). At the station at $28.6^{\circ} \mathrm{N} 65.1^{\circ} \mathrm{W}$, Trichodesmium

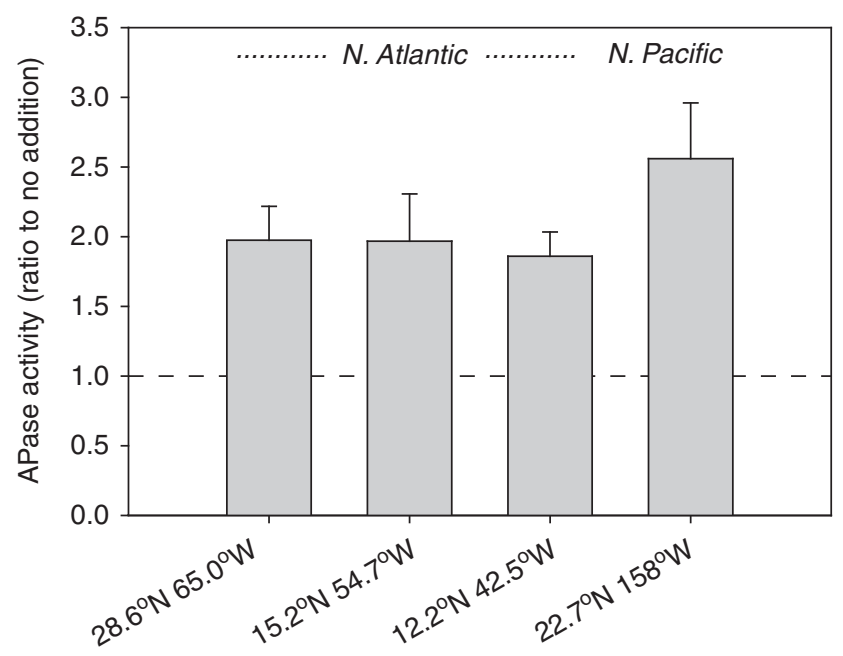

Figure 1 APase activity of Trichodesmium colonies in response to amendment with a cocktail of saturated, long-chain AHLs (C10HSL, C12-HSL and C14-HSL) in the North Atlantic and North Pacific. Error bars indicate the magnitude of the range for triplicate incubations. As the assays were conducted with slightly different methods in the North Atlantic and North Pacific, data are presented as ratios to the no amendment control incubations. The horizontal dashed line represents no response to the amendments.

colonies were also assayed using a cell-specific APase method (Dyhrman et al., 2002), and microscopic inspection clearly showed APase activity by epibionts in the colonies (Figure 2), particularly in the colonies exposed to the AHL cocktail (although this method is qualitative and not amenable to rigorous statistical comparisons (Hynes et al., 2009)). Given this observation, and the fact that available genomes from cyanobacteria, including Trichodesmium, lack clear homologs of genes encoding known AHL receptors (Case et al., 2008), we posit that the increase in APase activity (Figure 1) primarily reflected the response of bacterial epibionts and not the response of Trichodesmium. Although Trichodesmium does contain genes that align weakly at the amino acid level to authentic LuxR homologs, the key residues in the AHL-binding regions (Vannini et al., 2002; Pantankar and González, 2009) are absent, indicating that these Trichodesmium genes are unlikely to have AHLbinding functionality (Supplementary Figure 3). It should be noted that protein expression in a terrestrial, epilithic cyanobacterium changed in response to exogenous AHLs (Sharif et al., 2008), although enhanced APase expression was not observed and it is unknown if this particular cyanobacterium possesses a LuxR homolog.

We conducted a similar experiment in the oligotrophic North Pacific. APase activity is still frequently detected in Trichodesmium colonies in this region (Hynes et al., 2009), even though the phytoplanktonic community is not thought to be limited by phosphorus (Van Mooy and Devol, 2008; Duhamel et al., 2010) and dissolved phosphate is 



Figure 2 Representative photomicrographs of Trichodesmium colonies from the North Atlantic showing the cell-specific response to an enzyme labeled fluorescence assay of APase activity. The bright white and green areas on or near the orange autofluorescent Trichodesmium trichomes indicate localized APase activity. Left: endogenous Trichodesmium APase activity from a colony that did not receive an AHL amendment. Right: a colony from an incubation amended with the AHL cocktail, which shows the APase activity of epibiotic bacteria.



Figure 3 APase activity of Trichodesmium colonies in response to various AHL and AI-2 amendments (shown in legend) at a station in the North Pacific Ocean. Error bars indicate the magnitude of the range for triplicate incubations. Data are presented as ratios to the no amendment control incubations. The horizontal dashed line represents no response to the amendments.

more abundant than in the North Atlantic (Wu et al., 2000; Cavender-Bares et al., 2001; Hynes et al., 2009). In the North Pacific, we observed the same approximate doubling in APase activities in response to the long-chain AHL cocktail amendment as we observed in the North Atlantic (Mann-Whitney, $P=0.0495$; Figure 1). This result suggests that in addition to phosphate (Sohm et al., 2008; Hynes et al., 2009), APase activity within Trichodesmium colonies may be influenced by AHL-based QS. Furthermore, our observations of AHL-stimulated APase activity in both oceans suggest that this phenomenon could be globally distributed.

Incubations in the North Pacific were also amended with C8-HSL and 3-oxo-C8-HSL to distinguish possible differences in the effects of saturated and functionalized AHLs on APase activity
(Figure 3). The C8-HSL amendment yielded nearly the same response as the saturated, long-chain cocktail, whereas the 3-oxo-C8-HSL had little effect. This result suggests that the saturated AHLs observed in marine cyanobacterial mats (Decho et al., 2009) are recognized by Apase-producing epibionts, whereas the 3-oxo-functionalized AHLs are not. This result also indicates that the increase in APase activity that we observed in incubations amended with saturated AHLs (Figures 1 and 3) is a response to the specific signaling properties of those AHLs and is not a response to the potential nutritional value that would be common to all AHL molecules (e.g. dissolved organic nitrogen).

Attenuation of APase activity by AI-2

We also conducted incubations amended with (S)-4,5-dihydroxy-2,3-pentanedione (DPD), the molecule that spontaneously converts to AI-2 QS molecules in seawater (Chen et al., 2002; Miller et al., 2004; Supplementary Figures 1 and 4); AI-2 is thought to be a universal interspecies bacterial QS signal (Chen et al., 2002; Henke and Bassler, 2004; Miller et al., 2004). We observed that amendments of AI-2 appeared to attenuate APase activity (MannWhitney; $P=0.0495$; Figure 3). Furthermore, in incubations amended with both AI-2 and C8-HSL, the AI-2 amendment appeared to counteract the stimulation of APase activity by C8-HSL. Thus, saturated AHLs and AI-2 appeared to have opposing roles in the modulation of APase activity within Trichodesmium consortia. We speculate that one subpopulation of bacteria was using AHL-based QS to upregulate APase activity, whereas another presumably broader subpopulation was using AI-2 to do the opposite. An alternative explanation is that a single subpopulation simultaneously employed AHLs to upregulate APase activity when it benefitted themselves (i.e., efficiency sensing; Hense et al., 2007), but used the universal AI-2 signaling molecule to downregulate APase activity in situations 

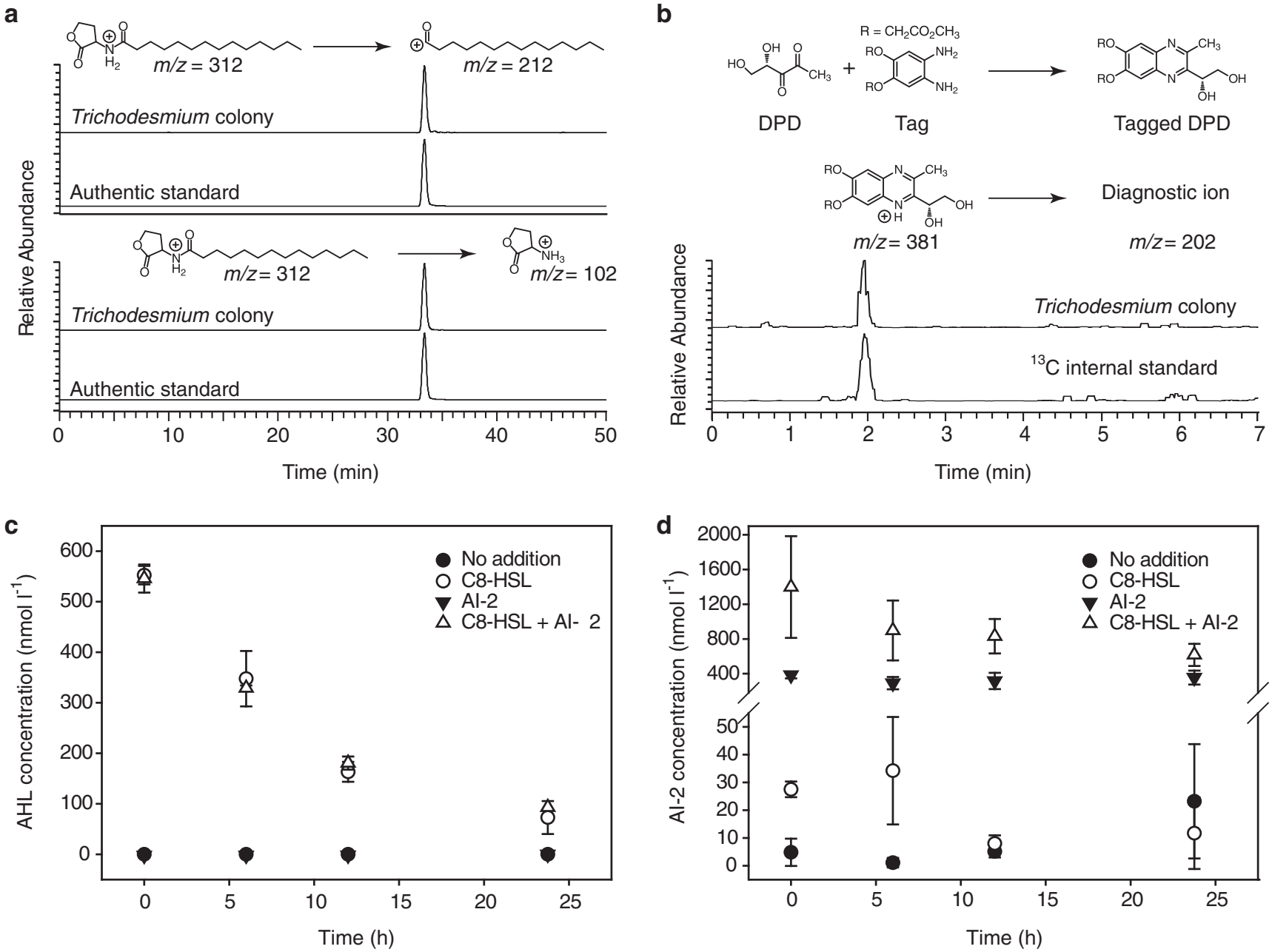

Figure 4 AHL and AI-2 in Trichodesmium colonies and amendment experiments. (a) HPLC/MS/MS chromatograms showing the presence of C14-HSL in Trichodesmium colonies. The top chromatogram shows the selected reaction monitoring (SRM) transition from the parent ion of C14-HSL to the acyl chain ion, whereas the bottom chromatogram shows the transition to the lactone ring ion. (b) Chromatogram showing the SRM transition from the parent ion of tagged DPD to a selective fragment ion. Scheme for the tagging of AI-2 is also shown. Tagging is necessary to both stabilize the molecule and make AI-2 amenable to HPLC/MS/MS detection (Campagna et al., 2009). (c and d) Plots showing the concentrations of C8-HSL and AI-2 through time in incubations containing Trichodesmium colonies. Amendments are shown in the legend. Error bars indicate the magnitude of the range for triplicate incubations.

where overall cell abundances were greater and, thus, other competing subpopulations might benefit.

\section{Presence and fate of AHLs and AI-2}

Using HPLC/MS/MS, we analyzed Trichodesmium colonies collected on the North Pacific cruise and found that both C14-HSL and AI-2 (via DPD derivatization; Campagna et al., 2009) were present (Figure 4; these molecules were absent in all process blanks). In natural seawater, AHLs are short-lived and subject to both abiotic lactonolysis and enzymatic degradation (Decho et al., 2009; Hmelo and Van Mooy, 2009; Tait et al., 2009b). Thus, the presence of AHLs in Trichodesmium colonies indicates that QS was active among epibiotic bacteria. As mentioned above, C14-HSL was also observed in cultures of epibionts, lending further support to the idea that saturated, long-chain AHLs may be ubiquitous QS molecules in Trichodesmium colonies. Until this study, AI-2 had yet to be observed in a marine environment, and both its half-life and functional role in mixed communities were largely unknown.

We also quantified C8-HSL and AI-2 in the aforementioned incubations by HPLC/MS/MS and found that the turnover rates of these signaling molecules in Trichodesmium colonies varied (Figure 4). We observed a rapid decline in C8-HSL concentration with the measured half-life $\left(t_{1 / 2}=7.6 \pm 0.4 \mathrm{~h}\right)$ being much shorter than expected from abiotic lactonolysis alone $\left(\mathrm{t}_{1 / 2}=25.6 \pm 1.9 \mathrm{~h}\right.$; Hmelo and Van Mooy, 2009); this observation is indicative of active enzymatic degradation (i.e., quorum quenching) of AHLs by members of the Trichodesmium consortia (Figure 4). Indeed, the open-ring by-products of lactonolysis 
were scarce in the incubations and their accumulation accounted for only about $2.0 \pm 0.4 \%$ of the C8-HSL that degraded during the incubations (Supplementary Figure 5). This result shows that additional AHL degradation pathways such as enzymatic hydrolysis at acyl-amide bonds (Decho et al., 2011 and references therein, Leadbetter and Greenberg, 2000) were dominant in our incubations. The halflife of C8-HSL was the same whether AI-2 was added to the incubations or not, and thus, quorum quenching of AHLs was unaffected by AI-2.

In contrast to AHLs, AI-2 was relatively stable by itself. However, when incubations were additionally amended with C8-HSL, we observed an initial threefold spike in AI-2 concentrations, followed by a rapid reduction $\left(t_{1 / 2}=18.6 \pm 7.3 \mathrm{~h}\right.$; Figure 4$)$. The observed initial spike in AI-2 concentrations is consistent with AHL-stimulated induction of AI-2 synthesis, whereas the subsequent decrease could be the result of AHL-stimulated quorum quenching of AI-2, either by extracellular degradation or by uptake via a low-affinity transporter and subsequent intracellular degradation. We know of no previous evidence to support either of these mechanisms, although it is recognized that some bacteria (e.g., Vibrio harveyi and Vibrio fischeri) utilize both AHLs and AI-2 to synergistically regulate behavior (Henke and Bassler, 2004; Lupp and Ruby, 2004) and that others (e.g., Pseudomonas aeruginosa and Escherichia coli) are able to degrade AHLs and AI2 (Xavier and Bassler, 2005; Bokhove et al., 2010). We speculate that the observed quorum quenching of both AHLs and AI-2 is an indication that microbes within the consortia were attempting to employ chemical warfare to disrupt QS regulation of APase activity.

\section{Conclusions}

Our results suggest that members of Trichodesmium consortia use QS to coordinate the processing and acquisition of phosphorus, a critical nutrient resource in oligotrophic open-ocean environments. Although APase activity in phytoplankton is canonically regulated by the availability of phosphate (Perry, 1972), our data indicate that microscale microbial interactions (e.g., Hewson et al., 2009; Malfatti and Azam, 2009) may also be important to the success of Trichodesmium in obtaining phosphate in the oligotrophic ocean. APase activity in Trichodesmium colonies may be detectable even when phosphate is relatively abundant (Sohm et al., 2008; Hynes et al., 2009), and our findings indicate that QS could be responsible for this observation. A recent metatranscriptomic study revealed the potential for a high degree of signal processing and information exchange amongst epibionts (Hewson et al., 2009), but at this time, we cannot conclude with any certainty how QS-regulated APase activity impacts the quantity of phosphorus available to
Trichodesmium, or whether rates of $\mathrm{CO}_{2}$ or $\mathrm{N}_{2}$ fixation are ultimately affected by QS. Clearly, in addition to QS, the bioavailability of phosphate and dissolved-organic phosphorus in situ will also affect APase activity. It has been suggested that Trichodesmium colonies are sources of dissolved inorganic and organic nutrients to surrounding waters (Nausch, 1996; Capone et al., 2005). Therefore, the outcome of the QS-regulated phosphorus cycling within Trichodesmium consortia could have profound impacts on the productivity of the broader planktonic community and on the exchange of phosphorus between organic and inorganic reservoirs in the oligotrophic surface ocean.

\section{Acknowledgements}

We thank the captain and crew of the R/V Oceanus, R/V Atlantic Explorer and R/V Kilo Moana, as well as $\mathrm{M}$ Lomas, T Miller, K Popendorf, M Church, D Karl, $\mathrm{P}$ Williams and L Wurch for their generous assistance. We also thank H Fredricks for assistance with HPLC/MS analyses and members of the Van Mooy laboratory for comments on an earlier version of this paper. This project was supported by an Office of Naval Research Award to BASVM (N0014-06-1-0134) and United States National Science Foundation awards to BASVM and TJM (OCE0825407), EAW (OCE-0962209) and STD (OCE-0925284; Center for Microbial Oceanography: Research and Education). SRC and ALM were supported by start-up funds provided by the University of Tennessee.

\section{References}

Bokhove M, Jimenez PN, Quax WJ, Dijkstra BW. (2010). The quorum-quenching $\mathrm{N}$-acyl homoserine lactone acylase PvdQ is an Ntn-hydrolase with an unusual substrate-binding pocket. Proc Natl Acad Sci USA 107: 686-691.

Campagna SR, Gooding JR, May AL. (2009). Direct quantitation of the quorum sensing signal, autoinducer-2, in clinically relevant samples by liquid chromatography - tandem mass spectrometry. Anal Chem 81: 6374-6381.

Capone DG, Zehr JP, Paerl HW, Bergman B, Carpenter EJ. (1997). Trichodesmium, a globally significant marine cyanobacterium. Science 276: 1221-1229.

Capone DG, Burns JA, Montoya JP, Subramaniam A, Mahaffey C, Gunderson $\mathrm{T}$ et al. (2005). Nitrogen fixation by Trichodesmium spp.: an important source of new nitrogen to the tropical and subtropical North Atlantic Ocean. Global Biogeochem Cycles 19: GB2024.

Case RJ, Labbate M, Kjelleberg S. (2008). AHL-driven quorum-sensing circuits: their frequency and function among Proteobacteria. ISME J 2: 345-349.

Cavender-Bares KK, Karl DM, Chisholm SW. (2001). Nutrient gradients in the western North Atlantic Ocean: relationship to microbial community stucture and comparison to patterns in the Pacific Ocean. Deep-Sea Res I 48: 2373-2395. 
Chen X, Schauder S, Potier N, Van Dorsselaer A, Pelczer I, Bassler BL et al. (2002). Structural identification of a bacterial quorum-sensing signal containing boron. Nature 415: 545-549.

Decho AW, Visscher PT, Ferry J, Kawaguchi T, He L, Przekop KM et al. (2009). Autoinducers extracted from microbial mats reveal a surprising diversity of $\mathrm{N}$-acylhomoserine lactones (AHLs) and abundance changes that may relate to diel pH. Environ Microbiol 11: 409-420.

Decho AW, Frey RL, Ferry JL. (2011). Chemical challenges to bacterial AHL signaling in the environment. Chem Rev 111: 86-99.

Duhamel S, Dyhrman ST, Karl DM. (2010). Alkaline phosphatase activity and regulation in the North Pacific subtropical gyre. Limnol Oceanogr 55: 1414-1425.

Dyhrman ST, Webb EA, Anderson DM, Moffett JW, Waterbury JB. (2002). Cell-specific detection of phosphorus stress in Trichodesmium from the western North Atlantic. Limnol Oceanogr 47: 1832-1836.

Farrand SK, Qin Y, Oger P. (2002). Quorum-sensing system of Agrobacterium plasmids: analysis and utility. Meth Enzym 358: 452-484.

Henke JM, Bassler BL. (2004). Three parallel quorumsensing systems regulate gene expression in Vibrio harveyi. J Bacteriol 186: 6902-6914.

Hense BA, Kuttler C, Müller J, Rothballer M, Hartmann A, Kreft J-U. (2007). Does efficiency sensing unify diffusion and quorum sensing? Nat Rev Microbiol 5: 230-239.

Hewson I, Poretsky RS, Dyhrman ST, Zielinski B, White AE, Tripp HJ et al. (2009). Microbial community gene expression within colonies of the diazotroph, Trichodesmium, from the southwest Pacific Ocean. ISME J 3: 1286-1300.

Hmelo L, Van Mooy BAS. (2009). Kinetic constraints on acylated homoserine lactone-based quorum sensing in marine environments. Aquat Microb Ecol 54: 127-133.

Hmelo L, Mincer TJ, Van Mooy BAS. Possible influence of bacterial quorum sensing on the hydrolysis of sinking particulate organic carbon in marine environments. Environ Microbiol Reports (in press).

Hmelo LR. (2010). Microbial interactions associated with biofilms attached to Trichodesmium spp. and detrital particles in the ocean. Ph.D. thesis, Massachusetts Institute of Technology - Woods Hole Oceanographic Institution Joint Program in Oceanography/Applied Ocean Engineering, Woods Hole, USA.

Hoppe H-G. (1993). Use of fluorogenic model substrates for extracellular enzyme activity (EEA) measurement in bacteria. In: Kemp PF, Sherr BF, Sherr EB, Cole JJ (eds). Handbook of Methods in Aquatic Microbial Ecology. CRC Press: Boca Raton.

Hynes AM, Chappell PD, Dyhrman ST, Doney SC, Webb EA. (2009). Cross-basin comparison of phosphorus stress and nitrogen fixation in Trichodesmium. Limnol Oceanogr 54: 1438-1448.

Karl DM, Björkman KM, Dore JE, Fujieki L, Hebel DV, Houlihan $\mathrm{T}$ et al. (2001). Ecological nitrogen-tophosphorus stoichiometry at station ALOHA. DeepSea Res II 48: 1529-1566.

Krauk JM, Villareal TA, Sohm JA, Montoya JP, Capone DG. (2006). Plasticity of N:P ratios in laboratory and field populations of Trichodesmium spp. Aquat Microb Ecol 42: 243-253.
Krishnamurthy A, Moore JK, Zender CS, Luo C. (2007). Effects of atmospheric inorganic nitrogen deposition on ocean biogeochemistry. J Geophys Res 112: G02019.

Leadbetter JR, Greenberg EP. (2000). Metabolism of acyl-homoserine lactone quorum-sensing signals by Variovorax paradoxus. J Bacteriol 182: 6921-6926.

Lomas MW, Burke AL, Lomas DA, Bell DW, Shen C, Dyhrman ST et al. (2010). Sargasso Sea phosphorus biogeochemistry: an important role for dissolved organic phosphorus (DOP). Biogeosciences 7: 695-710.

Lupp C, Ruby EG. (2004). Vibrio fischeri LuxS and AinS: comparitive study of two signal synthases. J Bacteriol 186: 3873-3881.

Malfatti F, Azam F. (2009). Atomic force microscopy reveals microscale networks and possible symbioses among pelagic marine bacteria. Aquat Microb Ecol 58: 1-14.

Miller ST, Xavier KB, Campagna SR, Taga ME, Semmelhack MF, Bassler BL et al. (2004). Salmonella typhimurium recognizes a chemically distinct form of the bacterial quorum-sensing signal Al-2. Molecular Cell 15: 677-687.

Mills MM, Ridame C, Davey M, La Roche J. (2004). Iron and phosphorus co-limit nitrogen fixation in the eastern tropical North Atlantic. Nature 429: 292-294.

Moutin T, Van Den Broeck N, Beker B, Dupouy C, Rimmelin P, Le Bouteiller A. (2005). Phosphate availibility controls Trichodesmium spp. biomass in the SW Pacific Ocean. Mar Ecol Prog Ser 297: 15-21.

Nausch M. (1996). Microbial activities on Trichodesmium colonies. Mar Ecol Prog Ser 141: 173-181.

Orchard ED, Webb EA, Dyhrman ST. (2009). Molecular analysis of the phosphorus starvation response in Trichodesmium spp. Environ Microbiol 11: 2400-2411.

Orchard ED, Ammerman JW, Lomas MW, Dyhrman ST. (2010). Dissolved inorganic and organic phosphorus uptake in Trichodesmium and the microbial community: The importance of phosphate ester in the Sargasso Sea. Limnol Oceanogr 55: 1390-1399.

Paerl HW, Bebout BM, Prufert LE. (1989). Bacterial associations with marine Oscillatoria sp. (Trichodesmium sp.) populations: ecophysiological implications. J Phycol 25: 773-784.

Pantankar AV, González JE. (2009). Orphan LuxR regulators of quorum sensing. FEMS Microbiol Rev 33: 739-756.

Perry MA. (1972). Alkaline phosphatase activity in subtropical Central North Pacific waters using a sensitive fluorometric method. Mar Biol 15: 113-119.

Sañudo-Wilhelmy SA, Kustka AB, Gobler CJ, Hutchins DA, Yang M, Lwiza K et al. (2001). Phosphorus limitation of nitrogen fixation by Trichodesmium in the central Atlantic Ocean. Nature 411: 66-69.

Sharif DI, Gallon J, Smith CJ, Dudley E. (2008). Quorum sensing in cyanobacteria: N-octanoyl-homoserine lactone release and response, by the epilithic colonial cyanobacterium Gloethece PCC6909. ISME J 2: 1171-1182.

Sheridan CC, Steinberg DK, Kling GW. (2002). The microbial and metazoan community associated with colonies of Trichodesmium spp: a quantitative survey. J Plankton Res 24: 913-922.

Sohm JA, Capone DG. (2006). Phosphorus dynamics of the tropical and subtropical North Atlantic: Trichodesmium spp. versus bulk plankton. Mar Ecol Prog Ser 317: 21-28. 
Sohm JA, Mahaffey C, Capone DG. (2008). Assessment of the relative phosphorus limitation of Trichodesmium spp. in the North Pacific, North Atlantic, and north coast of Australia. Limnol Oceanogr 53: 2495-2502.

Tait K, Hutchison Z, Thompson FL, Munn CB. (2009a). Quorum sensing signal production and inhibition by coral-associated vibrios. Environ Microbiol Reports 2: 145-150.

Tait K, Williamson H, Atkinson S, Williams P, Cámara M, Joint I. (2009b). Turnover of quorum sensing signal molecules modulates cross-kingdom signalling. Environ Microbiol 11: 1792-1802.

Van Mooy BAS, Devol AH. (2008). Assessing nutrient limitation of Prochlorococcus in the North Pacific subtropical gyre by using an RNA capture method. Limnol Oceanogr 53: 78-88.

Vannini A, Volpari C, Gargioli C, Muraglia E, Cortese R, De Francesco R et al. (2002). The crystal structure of the quorum sensing protein TraR bound to its autoinducer and target DNA. EMBO J 21: 4393-4401.
Wagner-Döbler I, Thiel V, Eberl L, Allgaier M, Bodor A, Meyer S et al. (2005). Discovery of complex mixtures of novel long-chain quorum sensing signals in freeliving and host-associated marine alphaproteobacteria. Chembiochem 6: 2195-2206.

Webb E, Jakuba R, Moffet J, Dyhrman S. (2007). Molecular assessment of phosphorus and iron physiology in Trichodesmium populations from the western central and western South Atlantic. Limnol Oceanogr 52: 2221-2232.

White AE, Spitz YH, Karl DM, Letelier RM. (2006). Flexible elemental stoichiometry in Trichodesmium spp. and its ecological implications. Limnol Oceanogr 51: 1777-1790.

Wu J, Sunda W, Boyle EA, Karl DM. (2000). Phosphate depletion in the western North Atlantic Ocean. Science 289: 759-762.

Xavier KB, Bassler BL. (2005). Interference with AI-2-mediated bacterial cell-cell communication. Nature 437: 750-753.

Supplementary Information accompanies the paper on The ISME Journal website (http://www.nature.com/ismej) 